\title{
Sobre a Marcha Mundial das Mulheres: entrevista com Nalu Faria
}

\author{
Carmen Susana Tornquist \\ Universidade do Estado de Santa Catarina \\ Soraya Resende Fleischer \\ Universidade de Brasília
}

Os participantes dos fóruns sociais mundiais, dos fóruns sobre meio ambiente, da Marcha das Margaridas, dos 8 de marços e de outros movimentos sociais, de maneira geral, sabem o que significam as coloridas bandeiras e as "batucadas da marcha" que antecedem as conferências e as mesasredondas. Entrevistamos a feminista Nalu Faria, que atualmente coordena a Marcha Mundial das Mulheres (MMM) no Brasil.

Nalu Faria é psicóloga, com especialização em Psicodrama Pedagógico (Getep) e em Psicologia Institucional (Sedes Sapientiae). Atua na Sempreviva Organização Feminista (SOF) desde 1986, na qual desenvolve atividades de assessoria e formação feminista com grupos de mulheres, ONGs e gestores públicos. Coordenou várias publicações da SOF, como o boletim Mulher e Saúde (1993 a 2002), a coleção Cadernos Sempreviva (desde 1997) e o boletim Folha Feminista (desde 1999). Com Sonia Alvarez e Miriam Nobre, organizou o dossiê "Feminismos no Fórum Social Mundial" para a Revista Estudos Feministas, publicada em 2003. É autora de vários artigos sobre o movimento de mulheres, entre eles "O feminismo latinoamericano e caribenho: perspectivas diante do neoliberalismo". Foi integrante do Conselho Diretor da Fundação Perseu Abramo de 1996 a 2004.

Nesta entrevista procuramos conhecer como se articula no Brasil e em outros países do mundo e quais são os objetivos dessa rede de movimentos sociais (como pode ser classificada 
a MMM), bem como sua conexão com os movimentos altermundialista, campesino e ambientalista com os quais tem uma estreita parceria e compartilha agenda de mobilizações. Esta entrevista foi realizada, em Porto Alegre, nas dependências do Sindicato dos Bancários durante um encontro de mulheres da Democracia Socialista, em uma manhã de maio de 2011. 
Soraya Resende Fleischer: Nalu, obrigada por ter aceitado nosso convite. Para começar, você poderia nos contar um pouco de sua trajetória biográfica, como chegou ao feminismo e à participação política? Como você articula sua trajetória no feminismo com sua formação e atuação atual?

Nalu Faria: Eu vivi em Água Comprida, um pequeno município a $40 \mathrm{~km}$ de Uberaba, no Triângulo Mineiro, até o fim do ensino fundamental. Estudei o ensino médio e a faculdade em Uberaba. Cursei psicologia, entre 1978 e 1982, nas Faculdades Integradas de Uberaba (FIUBE), hoje UNIUBE. No primeiro ano comecei a participar do movimento estudantil a partir da luta pelo passe estudantil no transporte público. E logo em seguida entrei no Centro Acadêmico e no Diretório Central dos Estudantes (DCE). Em 1980 fizemos o primeiro 8 de março em Uberaba, nessa retomada do movimento de mulheres. Depois houve a criação de uma entidade da qual participei, chamada Centro Informação da Mulher (CIM), e também participei do PT desde a sua fundação. Vim para São Paulo, no final de 1983, e aqui, a partir da minha militância na Democracia Socialista (DS), tendência interna do PT, passei a participar de um debate mais estruturado sobre o feminismo. Desenvolvi minha militância no PT, no trabalho de mulheres nos sindicatos e na Central Única dos Trabalhadores (CUT), e, a partir de 1986, passei a atuar na Sempreviva Organização Feminista (SOF) e, portanto, com muita presença no movimento popular.

Atuo na SOF desde 1986. Nesse período, atuava no trabalho com as mulheres dentro do movimento sindical na CUT. Depois que fui para a SOF, que tinha uma atuação nos bairros das zonas sul e leste de São Paulo, continuei acompanhando a Comissão Nacional sobre a Mulher Trabalhadora (CNMT) na CUT. No final de 1989, a SOF foi convidada pelo Instituto de Formação Cajamar a organizar cursos de formação para mulheres. O Instituto Cajamar era uma escola de formação destinada a militantes do PT, do movimento sindical e popular, que funcionou até 1996. Formamos um grupo de que participavam representantes do Instituto Cajamar, da CNMT da CUT, da Cedi (uma ONG na época) e da SOF. Os cursos do Cajamar foram muito importantes, pois envolviam mulheres do Brasil inteiro. E, a partir daí, nós nos tornamos referência para formação feminista de vários grupos em vários estados.

Ao longo dos anos 1990 na SOF, questionamos muito sobre qual deveria ser uma estratégia de construção do movimento de mulheres para incorporar os vários setores e também para ter uma agenda mais global que desse conta de pensar na totalidade da problemática das mulheres. Nesse momento a agenda mais geral do movimento girava em torno dos temas de saúde, direitos reprodutivos e violência. 
A partir dessa avaliação, propusemos organizar vários seminários que pudessem contribuir, de um lado, para pensar essa agenda mais geral e, de outro, que propiciassem uma maior articulação desses grupos, muito vinculados aos movimentos mistos que tinham uma atuação local e/ou setorial. Organizamos seminários sobre agricultura familiar, educação, saúde, economia, sempre buscando realizá-los com parcerias e com uma reflexão a partir do debate feminista em relação a esses temas.

Carmen Susana Tornquist: Você poderia falar sobre a Marcha Mundial das Mulheres (MMM), isto é, como esse movimento se organizou e qual a sua vinculação com ele?

NF: Foi nesse processo em 1998 que conhecemos a proposta da Marcha Mundial das Mulheres, que era uma iniciativa de mulheres do Quebec para realizar uma campanha mundial no ano 2000 contra a pobreza e a violência contra as mulheres. Avaliamos que era uma ótima oportunidade para intervir, por um lado, naquela conjuntura marcada pelas políticas neoliberais e, por outro, um movimento de mulheres absolutamente voltado para a agenda definida pela Organização das Nações Unidas (ONU) e o monitoramento das plataformas definidas em suas conferências.

A inspiração para a criação da Marcha Mundial das Mulheres partiu de uma manifestação realizada em 1995, no Quebec, no Canadá, quando 850 mulheres marcharam 200 quilômetros pedindo, simbolicamente, "Pão e Rosas". A ação marcou a retomada das mobilizações das mulheres nas ruas, fazendo uma crítica contundente ao sistema capitalista. Ao seu final, diversas conquistas foram alcançadas, como o aumento do salário mínimo, mais direitos para as mulheres imigrantes e apoio à economia solidária.

O Brasil participou da articulação da MMM desde seu primeiro encontro internacional em 1998, no Quebec. Nesse primeiro encontro internacional se definiu a plataforma centrada em 17 pontos contra a pobreza e 17 pontos contra a violência. A proposta foi realizar um abaixo-assinado em torno dessas reivindicações para ser entregue na ONU, no Banco Mundial e no Fundo Monetário Internacional (FMI) em 17 de outubro. Ou seja, a MMM iniciou como uma campanha lançada no dia 8 de março a 17 de outubro de 2000 (Dia Mundial de Luta contra a Pobreza).

No Brasil, em outubro de 1999, foi realizada a primeira reunião nacional, na qual constituímos a MMM no Brasil. Nessa reunião as mulheres da Confederação Nacional dos Trabalhadores na Agricultura (Contag) apresentaram a proposta de realizar a Marcha das Margaridas em agosto, em adesão à MMM. Essa foi a atividade mais massiva naquele ano de 2000, com a presença de 20 mil mulheres. Entre 8 de março e 17 de outubro 
de 2000, foram realizadas inúmeras atividades em todos os estados, sendo a maior delas a Marcha das Margaridas, organizada pelas trabalhadoras rurais da Contag e outras entidades em agosto daquele ano como forma de adesão à MMM. Foi a partir do impacto desse amplo processo de articulação que várias brasileiras fizeram parte daquelas que propuseram a continuidade da Marcha como um movimento permanente em nosso país.

A MMM trazia um debate crítico às causas estruturais da pobreza e também a possibilidade de construir uma articulação crítica pelas mulheres em relação à questão da economia. Na época, quem tinha mais proximidade com a organização da MMM do Quebec eram as mulheres da CUT. Foram elas que, no ano de 1998, chamaram reuniões para definir as representantes brasileiras para o primeiro encontro internacional realizado no Quebec, em outubro de 1998. Após essa reunião, voltamos muito comprometidas com a realização dessa Marcha e passamos a articular, em conjunto com a CUT, as condições para organizar nacionalmente, e isso incluiu mobilização, captação de recursos etc. A MMM insere-se nas ações contrárias à globalização capitalista pelo mundo, impulsionadas por movimentos de caráter anticapitalista que questionam os ditames desses organismos internacionais e daqueles que exaltam o livre-comércio. Esse processo levou ao empobrecimento das mulheres e cada vez mais à precarização na sua inserção no mercado de trabalho, comprometendo ainda mais sua autonomia econômica.

SRF: Nalu, você poderia explicar quais são as formas de organização interna da MMM? Há comitês, diretorias, eleições etc.?

NF: No Brasil, nós nos organizamos a partir de comitês estaduais que, em geral, são compostos de representantes de outros movimentos, por exemplo, sindical, grupos de base, moradia, estudantil. Também impulsionamos que se formem comitês locais em universidades, municípios, por exemplo. Mas muitas vezes o Comitê Estadual é também o local de militância para muitas mulheres.

Temos uma coordenação executiva com oito membros e uma coordenação nacional com representantes dos comitês estaduais, que são rotativas e definidas pelos estados. A SOF é a secretaria executiva, e somos responsáveis pela comunicação e por outras tarefas executivas. Para o acompanhamento nos estados, dividimos as tarefas entre SOF e Centro Feminista 8 de Março (CF8), de Mossoró, no Rio Grande do Norte, que é parte da executiva. Então, elas articulam mais a região Nordeste e nós, os outros estados. 
CST: Como é o sistema de financiamento/sustentação econômica da MMM no Brasil, assim como nos outros países?

NF: A MMM é um movimento com poucos recursos. Nos países isso se dá de diferentes formas. Logicamente uma parte tem apoio da Cooperação Internacional, mas também há muitos recursos nacionais e também iniciativas de autossustentação. Há países na África, tal como Burkina Faso, com os quais todas as militantes da base contribuem regularmente, além de elas terem um café internet. No caso do Secretariado Internacional, tem apoio da Cooperação Internacional e há uma contribuição das coordenações nacionais.

CST: Quais são os países que participam da Marcha e de que forma?

NF: Em 2000, 167 países aderiram. Depois, quando se definiu continuar como um movimento permanente, diminuíram os países. Hoje tem coordenações nacionais em 60 países e grupos de contato em outros 90 . Além disso, há diferentes formas de pertencimento. Em alguns países se dá uma dinâmica permanente, em outros se mobilizam como MMM a partir de chamadas internacionais, sobretudo as ações internacionais realizadas a cada cinco anos. Em alguns países, tal como o Brasil, a Marcha serviu como uma forma de articulação do movimento, outros aderiram a ela como uma campanha. Ou seja, um coletivo nacional que organizou a Marcha. A Marcha em nível internacional tem um comitê internacional, com dois representantes por continente, e um secretariado internacional, com uma coordenadora internacional. Desde 2006 o Secretariado Internacional está no Brasil. A coordenadora internacional é a Miriam Nobre, que é da equipe da SOF e participou do Comitê Internacional da MMM desde o inicio, assim como da construção no Brasil.

CST: Existem diferenças quanto aos países centrais e aos situados no Sul Econômico? Como é a relação da Marcha com as dimensões de classe e etnia? Essas dimensões se articulam ou atravessam os movimentos de mulheres/feministas?

NF: Um valor forte na MMM é a construção de consensos a partir de realidades muito diferentes, tanto econômicas quanto culturais, mas também de processos do movimento de mulheres no país. Um ponto de partida fundamental para isso é a visão comum sobre a necessidade de mudanças estruturais na sociedade e nas relações sociais para que se possa construir igualdade para as mulheres. Há uma profunda compreensão de que a igualdade só se dará se alcançar o conjunto das mulheres. Isso remete não só à incorporação da dimensão de 
classe, mas também às outras formas de opressão e discriminação com que vivem as mulheres. E a Marcha é um movimento construído a partir das mulheres de base, que têm na organização e na mobilização suas principais ferramentas; em função dessas realidades tão distintas e das formas de opressão que há em cada país. Muitas vezes em alguns países certos temas são mais difíceis de serem assumidos por todas, em particular o tema do aborto e da sexualidade lésbica.

CST: Você poderia abordar o tema da MMM e o processo das conferências internacionais da ONU da década de 1990?

NF: A Marcha se constituiu na contramão das conferências da ONU. A origem da MMM está vinculada à experiência da marcha chamada "Pão e Rosas", como comentei anteriormente. A motivação dessa Marcha foi justamente a avaliação do que significava o Tratado Norte-Americano de Livre Comércio (Nafta) para as mulheres em termos de mais empobrecimento. Ao mesmo tempo perceberam que, em mundo globalizado, se deveria construir uma resistência mundial. Então em 1995, quando a grande maioria dos movimentos sociais investia toda sua energia na IV Conferência Mundial da Mulher da ONU, realizada na China, as mulheres do Quebec iniciavam essa proposta de uma grande mobilização do movimento social a partir de uma agenda própria.

As mulheres que iniciaram a organização da Marcha estiveram na Conferência de Pequim com o objetivo de discutir a Marcha, e não com a visão de que ali era o espaço de definição da agenda que depois pautaria o monitoramento dessas definições. A preocupação era justamente como construir uma resposta a partir do movimento para a ofensiva conservadora em curso a partir das vitórias do neoliberalismo, com uma compreensão de como o patriarcado e o capitalismo se reforçam mutuamente. A meu ver, a MMM se constituiu como uma das mais importantes articulações do movimento feminista nos últimos anos. Um aspecto central para essa análise é o fato de ter possibilitado uma recomposição do movimento de mulheres a partir de uma mudança de agenda. Para isso é necessário retomar o que foi a dinâmica do movimento de mulheres no período anterior, em particular na América Latina. Muito marcado pelos debates que se seguiram após a Queda do Muro de Berlim e de não se reposicionar criticamente diante das profundas políticas de ajuste e da implementação do neoliberalismo, o movimento de mulheres entrou nessa dinâmica de ser propositivo, trabalhar em parceria, colocando como um grande horizonte o estabelecimento de políticas públicas, mas sem questionar os limites dados pelo modelo de Estado vigente. Portanto, oscilando entre uma dinâmica de se fazer o possível e de considerar como grandes avanços as plataformas 
aprovadas nas conferências da ONU, em que pese o seu grau de generalidade e de não questionamento do fato de que elas não entram nos aspectos estruturantes das desigualdades. Existem diferenças de como o movimento se moveu seja na América Latina, África ou Ásia, mas um dado é comum: as conferências da ONU foram os grandes espaços de confluências durante quase toda a década de 1990. E podemos dizer que, enquanto o movimento de mulheres se empenhava na implementação de políticas focais e da incorporação de gênero, o mercado organizava a vida das mulheres em todos os níveis, inclusive no nível subjetivo. E foi com essa dinâmica que a MMM rompeu, propondo em 1995, pleno ano de Pequim (ano de avaliação da IV Conferência Mundial da Mulher), uma grande mobilização que se diferenciava desse processo pelo método de organização e pela plataforma. Foi uma das primeiras manifestações em nível mundial que questionaram abertamente o neoliberalismo e propuseram mudanças estruturais, discutindo também o sistema capitalista e não apenas sua face neoliberal. Foi, portanto, constitutiva do movimento antiglobalização iniciado com as manifestações em Seattle. Para o feminismo significou mais, significou retomar um movimento amplo que coloca a questão de gênero e classe como coextensivos e coloca a necessidade de transformação global do modelo. Foi no dia 18 de outubro de 2000, logo após a entrega dos abaixo-assinados e das audiências na ONU e no FMI, que se propôs que a Marcha continuasse como um movimento permanente. Isso se deu a partir do que foi seu impacto em vários países para articulação e mobilização do movimento de mulheres. Mas não havia nada pensado, e a proposta foi de nos encontrarmos no primeiro Fórum Social Mundial (FSM) que estava sendo organizado para janeiro de 2001 , em Porto Alegre. Nesse primeiro fórum, a Marcha teve grande visibilidade, por ter realizado uma grande mobilização. Teve uma fala em uma das conferências, participamos da teleconferência com Davos e realizamos um seminário autogestionado com grande presença de mulheres. A Marcha se envolveu com todo o processo de luta contra o livre-comércio, e consideramos que foi parte da construção do movimento por outra mundialização e teve como centro a luta contra a globalização neoliberal. No Brasil, a Marcha se envolveu com peso na campanha contra a Área de Livre Comércio das Américas (Alca) e, a partir dessa participação, articulou o debate e a ação crítica à mercantilização do corpo e da vida das mulheres, ao mesmo tempo que organizou uma campanha pela valorização do salário mínimo como parte das lutas pela distribuição da renda no Brasil e, portanto, contra a pobreza. A luta contra a Alca e a Organização Mundial do Comércio (OMC) marcou toda nossa presença na América Latina e foi fundamental para a recomposição de um campo de esquerda 
na região e, em particular, no movimento de mulheres. Saímos de um debate sobre os impactos positivos e negativos da globalização e de uma possível Alca para uma visão antissistêmica e de crítica global ao modelo, ao mesmo tempo que recuperamos que a mobilização e a luta social são nossas principais ferramentas.

CST: O Fórum Social Mundial também foi um ponto importante para o desenvolvimento da Marcha?

NF: O processo do FSM foi fundamental. Mas desde o início nós, em conjunto com outros movimentos sociais, compreendemos esse espaço como um espaço geral em que se expressava uma grande variedade de visões com aspectos comuns e também conflitivos. [...] Mas era importante que os movimentos organizassem dentro do Fórum um espaço de articulação no qual se pudesse ir mais além e organizar ações conjuntas. Por isso desde o início investimos tanto nas atividades e ações do Fórum quanto na organização da Assembleia de Movimentos Sociais.

Do ponto de vista dos processos concretos, houve a participação da Marcha no Comitê Internacional do FSM, no qual desenvolvemos uma forte relação de aliança com a Via Campesina, através das lutas conjuntas contra a Alca e a OMC e a relação na Assembleia de Movimentos Sociais.

Articulamos também um processo de aliança entre movimentos de mulheres que se expressou, por exemplo, na organização de uma agenda comum nos fóruns sociais mundiais e também em ações conjuntas de mobilização.

A partir da Assembleia de Movimentos Sociais, se intensificaram essas alianças e a organização de ações conjuntas nas campanhas contra o livre-comércio, a OMC e a guerra de Bush, no Iraque. Muitos atores/atrizes que estavam envolvidos no processo contra a Alca também estavam envolvidos no processo de desenvolvimento da Assembleia de Movimentos Sociais, formando assim espaços de articulação nos quais atuam tanto a Via Campesina quanto os Amigos da Terra.

No Brasil, além da campanha contra a Alca, a partir de 2003 realizamos várias ações conjuntas contra os transgênicos, e também houve a partir de 2005 uma maior aproximação das mulheres do Movimento dos Trabalhadores Rurais Sem Terra (MST) com a MMM.

SRF: Como foi essa aproximação com o MST e a Via Campesina, você pode explicar um pouco mais? Que temas e lutas os aproximaram?

NF: Preciso retomar a segunda ação internacional da MMM em 2005, pois foi um momento importante. Houve a construção 
da Carta Mundial das Mulheres para a Humanidade, na qual apresentamos nossa visão de mundo que queremos construir e, por isso, aparecem os vários temas. O lançamento dessa ação se deu no Brasil com uma marcha de 30 mil mulheres em São Paulo. Nessa ação, que também foi de 8 de março a 17 de outubro de 2005, a Carta percorreu 50 países e, além dos debates e da mobilização, foi construída uma colcha feita a partir de retalhos em que cada país expressou sua visão da Carta. Essa ação teve um impacto muito grande diante dos outros movimentos também. A partir da avaliação sobre a ação nos diversos países, se realizou uma sistematização dos pontos mais discutidos e trabalhados nos países. Vimos que o tema da soberania alimentar tinha bastante peso, assim como a participação de camponesas. No Brasil já sabíamos disso, tanto pela participação das mulheres da Contag e do Movimento da Mulher Trabalhadora Rural do Nordeste (MMTR/NE), como também pela relação com mulheres da Via Campesina. Mas o que constatamos é que isso era uma realidade mais ampla, ou seja, em vários países participavam camponesas na MMM e tratavam do tema de soberania alimentar.

Nesse processo da aliança com a Via Campesina e os Amigos da Terra, e em particular para a construção de uma visão que integrasse uma visão feminista, ecológica na soberania alimentar, o Fórum Nyéléni para a Soberania Alimentar foi fundamental. A partir de um convite da Via, se construiu uma comissão organizadora ampla para a realização desse Fórum, que ocorreu no Mali, em 2007. No processo preparatório, fizemos um amplo processo de debate com as mulheres tanto no Brasil como na América Latina e no Caribe.

Nesse processo de debates, sempre procuramos construir uma aliança entre todas as mulheres envolvidas e mobilizadas, como, por exemplo, a construção de documentos em conjunto. Mas, sobretudo, nosso diálogo nos espaços mistos se dá a partir da aliança com as mulheres desses outros movimentos.

No ano de 2010, houve um seminário que juntou a MMM, a Via e os Amigos da Terra, com a participação das mulheres africanas e asiáticas que foi muito interessante. O objetivo era avaliar se houve avanços nas ações conjuntas e na construção dessa abordagem.

SRF: E é fácil trabalhar nesses "espaços mistos", como você denominou?

NF: Nesses processos, alguns temas são mais fáceis de serem trabalhados, como, por exemplo, a questão do trabalho, da crítica global ao modelo hegemônico de agricultura. Já os temas, tais como o do aborto e o da sexualidade, são mais difíceis de abordar. A questão da violência vem sendo crescentemente incorporada pelo conjunto dos movimentos sociais. As mulheres da Via Campesina, em 2008, em sua V 
Conferência Internacional, aprovaram a proposta de uma campanha contra a violência em relação às mulheres.

Do lado da MMM, temas como agroecologia e uma visão crítica da destruição da natureza estão mais incorporados. Na Europa, ocorre um aumento significativo de ações em conjunto com mulheres da Via Campesina. Existe um processo de fortalecimento que chamamos de processo de contaminação das agendas, ou seja, uma agenda contamina a outra, numa tentativa de abordagem global.

CST: Nas experiências e nas propostas de agricultura familiar e agroecologia, você acha que haveria certa "idealização" da família tradicional? Essa "idealização" poderia tencionar com ideais feministas de autonomia e liberdade das mulheres, bem como com o questionamento em relação aos padrões da família burguesa, heteronormativa etc.?

NF: O que devemos perceber é que, a partir das suas realidades socioculturais, as mulheres percebem e encontram seus processos, suas trajetórias. As camponesas possuem um debate mais desenvolvido tanto de crítica sistêmica ao modelo capitalista como de análise feminista na questão da agricultura e da participação no movimento. Isso se deu a partir de uma trajetória em que elas foram encontrando seus espaços, seu caminho de fazer o debate, afirmando questões com muito protagonismo na luta pelos direitos da terra, na resistência às empresas transnacionais que ocupam seus territórios e impõem seu modelo de agricultura capitalista. Elas foram reivindicando e visibilizando seus conhecimentos, seu papel e contribuição históricos na agricultura e, assim, avançando fronteiras. A luta dessas mulheres era para garantir a terra, ao mesmo tempo que questionavam a exclusão dos filhos nos processos de herança das esposas.

Acho que avançou inclusive no questionamento ao modelo de família idealizada, a família como espaço de harmonia, de complementaridade. A garantia de espaços de autoorganização das mulheres nos movimentos mistos é fundamental para $o$ debate entre elas para que possam aprofundar suas reflexões, colocar seus questionamentos, pensar formas conjuntas de ação. Creio que as mulheres avançaram mais do que os homens em relação ao debate de outro modelo que incorpore não só o feminismo, mas também uma visão ecológica. Isso faz parte também de um processo de conquista de mais autonomia.

CST: Quais as dificuldades que vocês têm encontrado para abordar o tema do aborto, uma vez que esse tema é considerado delicado nos movimentos de mulheres que não são declaradamente feministas? 
NF: Nesse processo das alianças, ainda tratamos pouco sobre o tema. Creio que o tema do aborto, em primeiro lugar, tem que ser trabalhado entre as mulheres e, a partir de um acúmulo, ir ampliando para outros setores. O que prevalece nesse caso é fortalecer os espaços nos quais discutimos entre mulheres o que levar para uma agenda geral. Mas isso também é relativo e depende do grau de articulação e mobilização que temos. Nesse caso, podemos citar que no Brasil e na América Latina o tema do aborto é parte da agenda da MMM. Nós temos colocado em todos os documentos sobre integração regional um item que propõe que um processo de integração dos povos só ocorrerá se as mulheres tiverem soberania sobre seus corpos e suas vidas. Em alguns documentos da Coordenação dos Movimentos Sociais (CMS) no Brasil colocamos a garantia do exercício dos direitos reprodutivos. Mas é fato que ainda falta muito para que o tema do direito ao aborto seja incorporado por todos. No Brasil, tanto a CUT quanto a UNE em geral, não só as mulheres, têm resolução em favor da descriminalização e da legalização do aborto. Em geral, nos países da África é onde sentimos mais dificuldades. Temos feito mais intercâmbio de experiências de como as mulheres vivem o aborto, mas ainda é difícil ações comuns, simultâneas em todo o mundo. No Brasil, é um pouco diferente, mas conseguimos expor, ampliar o debate dos direitos reprodutivos. É em um grupo grande, com vários países, que a polêmica aparece mais claramente.

SRF: No Brasil, na Marcha há uma maior representatividade de mulheres dos movimentos sociais do campo ou urbanos?

NF: A composição da MMM no Brasil é bastante diversificada. Como é um movimento bastante horizontal, temos dificuldade de ter dados muito exatos. O funcionamento cotidiano dos comitês estaduais é mais marcado pela presença das mulheres urbanas. Em muitos estados temos uma presença grande de jovens, em outros de mulheres da economia solidária, em outros de mulheres do movimento sindical. Em alguns estados temos uma forte dinâmica rural, como é o caso do Rio Grande do Norte, do Ceará, e cresce na Bahia. Além da grande presença das mulheres da Contag e do MMTR/NE.

Com as mulheres indígenas, existe diálogo e participação em alguns estados, tal como Roraima, Amazonas, Alagoas e, na Bahia, que está aumentando. No Brasil, ampliamos muito a participação das mulheres. A Marcha é um espaço de militância, muitas não participam de nenhum movimento, sindicato, mas são militantes da Marcha. Estamos incentivando muito a criação de comitês a partir das universidades, por exemplo. Desses comitês participam mulheres de todas as organizações e sindicatos. No entanto, nem todos os países 
possuem essa organização, ainda reproduzem a ideia de representatividade de entidades e instituições.

SRF: Então, na prática, no cotidiano do trabalho, a Marcha é composta da reunião de mulheres de várias ONGs, sindicatos, associações comunitárias, movimentos indígenas, universidades, associações de bairros periféricos etc., mas não necessariamente como "representantes" de cada um desses lugares. Seria isso?

NF: É isso mesmo. Na verdade temos uma mistura dessas coisas. Em alguns estados está mais organizada a partir de representações, mas não necessariamente algo formal, uma por organização, e sim aquelas que querem participar. Em outros prevalecem vários núcleos da Marcha por universidade, município etc.

CST: É o "feminismo de base", você concorda com essa ideia?

NF: Não. Temos uma visão de que existe um movimento de mulheres que incorpora vários setores e grupos, e não existe uma separação entre um movimento de mulheres e um movimento de feministas. Temos um movimento de mulheres com um setor feminista, e é a partir do processo de participação, de formação e de radicalização que o conjunto das mulheres vai incorporando de forma mais consciente e explícita o feminismo. Pois, em geral, as mulheres que estão nos movimentos enfrentam algum nível de confrontação com o patriarcado, imposição da divisão sexual do trabalho. Nós consideramos fundamental a incorporação da dimensão de classe e temos que pensar como fazer essa integração que altera tanto a dinâmica como a plataforma e as relações. Estamos mesmo organizando um livro sobre essa questão [feminismo de base] junto com a Universidade do País Basco.

SRF: Na última década, em que muitas lideranças feministas chegaram ao poder como vereadoras, deputadas, senadoras e gestoras do Executivo, você entende que há uma coerência com os princípios feministas?

NF: Quando uma pessoa opta em fazer parte de um governo, ela passa a fazer parte de uma gestão, por sua bagagem de conhecimento, por seu partido. E pode desenvolver muitas ações próximas das lutas do movimento das mulheres. Exemplo disso ocorre com os integrantes do PT, por exemplo. No momento em que assume um mandato, essa mulher irá desenvolver políticas coerentes com o seu discurso de quando era militante do movimento social dentro do partido. Mas entendemos que as companheiras feministas que neste momento fazem parte de 
um governo representam o governo e as forças que estão nele. No entanto, elas continuam tendo relação e podem fazer um diálogo com o movimento de mulheres. E nossa expectativa é de que essas companheiras feministas que estão no governo possam ter capacidade de diálogo com os setores populares, reconhecendo a importância do protagonismo do setor popular, no nosso caso das mulheres. Esperamos que sua forma de exercer seu cargo propicie também o protagonismo, isto é, crie espaço de debates, de intervenção, para que as mulheres que estão organizadas possam ter voz.

CST: Qual a visão da MMM em relação aos polêmicos projetos de infraestrutura que vêm sendo feitos na América do Sul e que sustentam o PAC brasileiro?

NF: O ponto de partida geral é a visão de qual modelo queremos construir. As perguntas básicas são o que produzir, como produzir, como consumir, como distribuir, como alterar a atual relação produção e reprodução? Essa relação com a re/ produção coloca sob a responsabilidade quase exclusiva das mulheres o trabalho de cuidados com a vida humana.

Temos duas questões bastante presentes: se falamos de energia, de infraestrutura, a pergunta é para que e para quem? A outra questão é como se tomam as decisões? Ou seja, nossa recusa é de tudo que está pensado para garantir o lucro das grandes empresas em detrimento de colocar o bem-estar de todos e todas como o centro do modelo e, portanto, um outro paradigma de sustentabilidade da vida humana.

Ou seja, na Marcha temos muitos questionamentos sobre o atual paradigma hegemônico baseado nessa ideia de desenvolvimento. Entendemos que não é um modelo sustentável, é baseado em valores de mercado, incompatíveis com a sustentabilidade da vida humana centrada no bemestar de todos e todas e de harmonia com a natureza. Para nós, a ideia que deve prevalecer é a do modelo de bem-estar, que deve estar voltado para todos e todas. É uma ideia de sociedade totalmente antagônica ao modelo hegemônico em que vivemos atualmente. Vivemos nesse modelo de desenvolvimento que não beneficia a todos e também não é um modelo desejado. Nossa dificuldade é estabelecer um debate, pois a globalização atingiu os setores da população numa rapidez surpreendente, mais rápido que nossa capacidade de gerar o debate. Só para dar um exemplo, em qualquer canto do país, em lugares de difícil acesso, em acampamentos, todas as pessoas possuem telefones celulares, que muitas vezes se tornaram a única maneira de se comunicar, mas ao mesmo tempo querem trocar o aparelho sempre por um novo e mais sofisticado. Precisamos analisar o que significa isso do ponto de vista das questões que hoje estamos pensando. Por isso nós 
entendemos que garantir essa transição é muito complexo perante os resultados da globalização. E tudo isso é, muitas vezes, paradoxal, pois as comunidades têm acesso ao celular, mas não acessam outros bens mais necessários e básicos de consumo e sobrevivência. É uma visão bastante consensual, em grande parte dos movimentos, de que temos que fazer a transição para outra matriz energética que não seja baseada nos combustíveis fósseis, que é necessário diversificar as fontes, buscar fontes renováveis e limpas, produzidas e gestionadas de forma descentralizada e democrática. Entendemos também que deve haver uma mudança do padrão de consumo. Nesse sentido, se no geral achamos que explorar gás é parte do modelo que queremos superar, mas o que significa hoje dizer que a Bolívia não explore seu gás? Acreditamos que precisamos aprofundar esse debate sobre a transição desse modelo. A velocidade do capitalismo brasileiro e a expansão de suas empresas hoje na região [cada vez mais na África], por exemplo, reforçam o modelo que questionamos das grandes obras, da exploração de minérios, do extrativismo etc.

Temos que pensar, primeiro, no bem-estar da população. $O$ Brasil possui potencial para construção de uma matriz energética descentralizada, usando outras fontes de energia. Nesse sentido, a resistência dos movimentos camponeses e indígenas nos deu muitas lições, visto que demonstrou como esses setores mais marginalizados podem resistir a situações muito complexas. Um exemplo foram as lições que aprendi com o Movimento dos Atingidos por Barragens (MAB) e a resistência. Morei numa região onde houve inundação a partir da construção de uma barragem que nem era tão próxima. E vi que um grande fazendeiro foi comprando o restante da terra não inundada e se tornou um grande proprietário na região. Mas é muito impressionante como esse modelo é perverso [...], é muito difícil reagir a esse processo. Ele é dado como o "custo do progresso", como dizem. Possuímos muita dificuldade de discutir de forma consistente esse projeto de transição dentro dos movimentos sociais, porque vivemos em meio a contradições. Por exemplo, a maioria dos movimentos apoia a exploração do Pré-Sal, mas questiona a usina de Belo Monte. $O$ que vamos pesar nessa balança?

SRF: Você poderia comentar sobre a contribuição da denominada economia feminista?

NF: Magdalena Leon, economista feminista equatoriana, traz com peso essa ideia de economia ampliada. Ela tem como referência concreta a experiência vivida no Equador, onde grande parte das práticas econômicas ainda é regida por outros valores que não monetários. No Brasil, o que ainda tem de economia não monetarizada está muito fragmentado. As 
mulheres do campo têm a sua produção no quintal. Contribuem no roçado, mas isso é visto como "ajuda". Elas realizam o trabalho doméstico e de cuidados, mas quando é vendida a safra, é o dinheiro que aparece. Não aparece o produto desses cuidados, dessa reprodução cotidiana.

A economia feminista traz esse debate do reconhecimento de que a economia vai além do mercantil e do monetário, coloca a necessidade de reconhecimento de uma contribuição econômica das mulheres no trabalho doméstico, de cuidados, para o autoconsumo. Dessa forma, além de incorporar, coloca essa necessidade de reconceituação do que é "economia" e do que é "trabalho" e questiona esse paradigma centrado no mercado. E reconceituar significa incorporar as práticas, os conhecimentos e as experiências das mulheres em tudo que historicamente foi construído. Hoje, na América Latina, está presente o debate do reconhecimento dos direitos com a natureza, toda a questão da Pachamama, principalmente pelos povos indígenas, e todo o debate na Bolívia, no Equador etc. Nós [as feministas] sempre tememos que isso nos levasse a uma questão essencialista de identificação da natureza com as mulheres em função da maternidade. No entanto, creio que esse diálogo com as sociedades indígenas não seja simplesmente incorporar uma visão da complementaridade entre masculino e feminino (que é outro aspecto presente nesse debate), mas também não é de confrontação. Hoje essa recuperação da questão de uma relação harmoniosa com a natureza significa confrontar o capitalismo patriarcal, racista, degradante do meio ambiente. Ou seja, reconhecer que os impactos sobre a natureza não são externos ao modelo econômico, assim como o trabalho doméstico e de cuidados também não o são. E nós temos compartilhado da análise de que o tempo e o trabalho das mulheres, tal como a natureza, são, por esse modelo, tidos como recursos inesgotáveis. Historicamente, as mulheres foram identificadas com a natureza e isso gerou muita desvalorização, sobretudo porque os homens foram identificados com a cultura. O debate é justamente avançar na crítica ao androcentrismo desse modelo, mas também ao antropocentrismo. Além disso, há também o debate sobre, por exemplo, a relação entre biodiversidade não só como da natureza, mas fruto das relações sociais, da interação entre ser humano e natureza.

CST: Vamos aproveitar e relacionar as suas duas últimas respostas, a difícil questão do desenvolvimento e os casos do Brasil e da Bolívia. Como fica a situação do desenvolvimento ao compararmos esses dois países, em sua opinião?

NF: Em abril de 2010, quando estivemos na Conferência de Cochabamba, ficamos impressionadas com a produção de 
alimentos e vimos que não era fruto de uma agricultura marcada pela Revolução Verde, uma vez que o peso da cultura e da economia camponesas ainda é muito significativo. O Brasil é fortemente marcado pela Revolução Verde, por monocultivos e pelo agronegócio. Felizmente, ainda existem muita resistência dos indígenas, quilombolas, ribeirinhos, agricultores familiares e cada vez mais o resgate da agroecologia. O problema, contudo, é a velocidade desse desenvolvimento, sobretudo se você pensar no ritmo e nas dificuldades que possuímos para recuperar as práticas de agroecologia. Observamos que, em geral, são as mulheres que incorporam primeiro as práticas agroecológicas. Isso acontece por vários motivos: o lugar das mulheres na agricultura é na produção do quintal, um lugar essencialmente propício para a agroecologia. Por outro lado, as mulheres foram excluídas da produção mecanizada da Revolução Verde. Então, elas não incorporaram as tecnologias de forma tão imediata, nem a relação com os bancos, com a comercialização com empresas. As mulheres ainda vendem seus produtos próximo à sua comunidade.

Em seus debates, as mulheres do MAB, por exemplo, reconhecem que, na venda da terra, o dinheiro não ficará com elas e que a subsistência vem dessa terra. Elas têm mais desconfiança do mercado, sabem que poderá surgir o endividamento, usam sua intuição. Com homens, devido à questão da força, já é o contrário. Eles acham que, com um pouco de dinheiro, vão se tornar empresários. As mulheres são ligadas à natureza e os homens à cultura? Essa não é nossa visão, e temos procurado entender essa relação das mulheres com a natureza a partir de suas práticas sociais concretas, através das relações de gênero e seu lugar na divisão social e sexual do trabalho. Mas é necessário entrar na seguinte questão: nem todas possuem essa relação com a natureza.

Já na agroecologia, elas estão participando dos espaços de formação, reuniões, trocas de experiências e saberes. E, pela primeira vez, elas verão o seu trabalho valorizado. Agora, esse é um processo contra-hegemônico e, portanto, mais lento que o capitalismo e sua voracidade pelo lucro. Creio que não é correto falar mais lento, mas a relação com o tempo é outra e se consideram, dessa forma, os tempos de regeneração da terra. Isso exige um forte reconhecimento por parte do Estado e o desenvolvimento de políticas públicas para a agroecologia, tendo como ponto central a necessidade de uma reforma agrária integral.

Quando as mulheres começam a se organizar no movimento agroecológico, elas começam a perceber de outra forma sua contribuição na agricultura, e isso contribui para uma consciência crítica sobre a dimensão de gênero. $E$, por sua vez, uma nova identidade, a partir de um processo coletivo no movimento, traz mudanças a essas mulheres. 
Ao mesmo tempo, a soberania alimentar só será efetiva se envolver a cidade e se desmantelar esse modelo industrial de agricultura que chega até a comercialização nos grandes supermercados.

Mas esse não é um processo fácil. Primeiro, porque as grandes metrópoles são mais complexas, as pessoas têm seus tempos muito ocupados, dificultando sua participação. Existem temas que na cidade são mais difíceis de serem trabalhados, tais como a ecologia, os modelos de consumo e a soberania alimentar. Colocamos o tema da soberania alimentar e de padrões de consumo como parte de nossas tarefas na Marcha a serem desenvolvidas nas cidades, com os movimentos sociais urbanos.

SRF: Você começou esta última resposta falando do Brasil e da Bolívia em termos de desenvolvimento e terminou trazendo uma reflexão sobre as mulheres do campo e sua participação na agroecologia. É interessante notar como esferas mais macroscópicas, relativas ao desenvolvimento econômico, possuem relações com esferas microscópicas e cotidianas. Qual é o impacto dessas novas trajetórias das mulheres rurais (e também urbanas) e do trabalho doméstico?

NF: O tema trabalho doméstico é complexo de abordar, mesmo dentro do movimento. Nós fizemos um esforço não só para incorporar esse tema em nossas análises, nas plataformas, mas também para discutir nas atividades de formação e no cotidiano dos grupos. Mas a questão da divisão do trabalho em casa, quando as mulheres são casadas e com filhos, é difícil abordar. Foi com isso que tentamos romper, pois achávamos que deveríamos ir além dos nossos panfletos, das nossas análises dentro da Marcha. E foi com esse objetivo que o incorporamos nas palavras de ordem da batucada. Por volta do ano de 2003, em uma ação da Marcha, quando eram gritadas as palavras de ordem como "violência", não tinha reação dos homens nas ruas. Mas quando gritávamos "João, João, cozinha seu feijão!" ou "José, José, cozinha se quiser!", eles reagiam. Uma atividade que utilizamos em atividades de formação é a de abrir esse debate perguntando se houve mudanças em relação ao trabalho doméstico depois que passaram a ser militantes. Essa foi uma das maneiras para visibilizar e fazer o debate político-econômico.

CST: A MMM tem uma reflexão acerca da indústria da beleza e do papel que ela joga tanto na subjugação das mulheres, mercantilizando os corpos e re/produzindo padrões de beleza que movimentam uma economia significativa no mundo, e no Brasil, em particular. O Brasil é um dos maiores consumidores de fármacos, desde psicotrópicos até os inibidores de apetite, e 
de produtos de beleza, campeão de cirurgias plásticas e onde o estereótipo da "mulher brasileira" tem um peso muito grande. Você poderia contar um pouco dessa reflexão, como começou e o que a Marcha está fazendo nesse sentido?

NF: Acho que nós da SOF tivemos uma contribuição nessa questão ao mesmo tempo que encontramos muita receptividade nesse tema. Em primeiro lugar, na SOF essa preocupação estava colocada desde antes da existência da MMM. Por exemplo, no boletim Mulher e Saúde, que publicamos na maior parte da década de 1990, tratamos esse tema junto com o debate de "reposição hormonal". Falávamos da imposição das cirurgias plásticas etc. Nós já abordávamos essa intensificação da mercantilização sem usar esse nome.

Na Marcha, buscamos trabalhar desde o início o que significava a globalização neoliberal para as mulheres. E naquele momento tínhamos todo um discurso do avanço do reconhecimento dos direitos das mulheres, os resultados das conferências da ONU (que já abordamos acima). Nós, então, na busca de construir uma análise que desse conta do que realmente acontecia, construímos essa abordagem de que, enquanto se reconheciam os direitos das mulheres nas conferências da ONU, o mercado ia reorganizando a vida das mulheres. Além disso, incorporamos a formulação de Danièle Kergoat sobre o fato de que a globalização criou uma dualidade entre as mulheres. Daniele afirma que, pela primeira vez na história do capitalismo, algumas mulheres tiveram acesso ao capital por elas mesmas e não em função de suas relações de parentesco e herança como filhas, esposas, amantes. Mas isso se deu em um momento que, para a grande maioria, significou ter trabalho precário e sem direitos, assim como mais sobrecarga com trabalho doméstico e de cuidados sob a diminuição dos direitos sociais no neoliberalismo.

Ser contra a mercantilização do corpo e da vida das mulheres significa combater a lógica que transforma as mulheres em objetos a serem comprados, vendidos ou mesmo tomados à força. A desconstrução dos mecanismos do mercado, da exploração do trabalho, das pressões da mídia, passando pelas novas e velhas formas de controle do corpo, são todos aspectos que vão ao coração do sistema capitalista e nos permitem, a partir de experiências cotidianas das mulheres, fazer relações entre as situações de opressão e o funcionamento da ordem econômica.

A MMM tem como um eixo estruturador de sua ação a luta contra o livre-comércio ou livre-mercado. Atuou na luta contra a OMC, denunciando que essa instituição não serve apenas para a regulação do comércio, mas tem como objetivo a mercantilização de todas as dimensões da vida. Na campanha contra a Alca, em 2002, a MMM elaborou como consignação 
"O mundo não é uma mercadoria! As mulheres também não!". Essa consignação se transformou em um grito da batucada feminista: "A nossa luta é todo dia: somos mulheres e não mercadoria!".

CST: E a relação entre a Marcha e a universidade? Como você vê essa relação?

NF:. Tentamos estabelecer relações que nos ajudem a pensar os desafios colocados para nós. Existem muitas/os acadêmicas/os que precisam de nossos materiais, que querem entender 0 processo. Mas nunca conseguirmos desenvolver bem a relação e avaliamos que temos essa dificuldade devido às agendas e à falta de tempo. Mas outra dificuldade é das/os próprias/os acadêmicas/os, por não terem mais ligações conosco. Na verdade precisamos de tempo e situações que alimentem essa relação. Atualmente a Marcha está envolvida num processo, no País Basco, junto à Universidade, em projeto de que participamos nós com a Via Campesina. Tem companheiras da MMM e da Via fazendo um máster o tema da cooperação. Estão desenvolvendo uma pesquisa para pensar a cooperação, e isso é bastante importante. No Brasil existem experiências muito esporádicas, devido a nossas dificuldades de encontrar mecanismos para essa intervenção, de um processo mais orgânico. Mas não é resistência nossa. No nosso caso, participamos de muitas entrevistas feitas por pesquisadores, mas temos pouco retorno. $\mathrm{E}$ deveria ser pensado na forma de retorno, poderia ser, por exemplo, na forma de debate. Mas também creio que temos um problema do ponto de partida: o que estudar. Sempre chegam com propostas do que querem estudar e somos as pesquisadas. Na verdade acho que seria importante uma definição conjunta de estudos que nos ajudasse a aprofundar determinadas questões que são consideradas desafios para nós.

CST: Você poderia abordar a conhecida "batucada" da MMM, qual seu significado e como foi escolhida como uma manifestação singular da Marcha?

NF: A batucada na MMM, como uma expressão de nossa ação feminista, iniciou com as mulheres do Rio Grande do Norte no FSM, em 2003. Essa experiência somou e inovou uma linguagem própria da MMM. Possibilitou ocupar plenamente o espaço público desde os nossos sons, que produzimos dos tambores e das latas, e de nossas vozes, com gritos que fortalecem uma ação feminista irreverente. O ritmo, o visual e a rebeldia da batucada feminista já apareceram nas manifestações do 8 de março de 2003 em alguns estados.

No Fórum Social Brasileiro, realizado em novembro de 2003, em Belo Horizonte, em uma manifestação conjunta com o acampa- 
mento da juventude, ocupamos o Carrefour e etiquetamos os produtos transgênicos. Nessa ação a batucada "estourou", dando o ritmo da intervenção com paródias críticas às músicas de propagandas de produtos alimentícios.

Ainda no ano de 2003 foram organizadas várias oficinas de pichação crítica aos cartazes sexistas, principalmente, de cervejas e de beleza. Nessas oficinas, voltadas principalmente para as jovens, se construiu uma reflexão sobre a imposição do padrão de beleza e como ele já está presente na juventude.

A proposta de construir uma "ofensiva contra a mercantilização do corpo e da vida", com o objetivo de articular e intensificar as ações que já eram realizadas em vários estados, surgiu em uma reunião das jovens na MMM. A ofensiva foi lançada em 2004 como uma ação permanente, e não como uma campanha que tem reivindicação específica. Sua estratégia inclui a reflexão e a elaboração de ações feministas contra o machismo na sociedade de mercado e se materializa em colagem de cartazes, intervenção em cartazes publicitários, ações de rua com batucada, debates sobre letras de música, publicidade na TV e em revistas e padrões de beleza. A luta contra a mercantilização foi o eixo orientador das ações do dia 17 de outubro de 2004, no Brasil. Vários estados realizaram ações relacionando a atuação das transnacionais à mercantilização da vida e do corpo das mulheres. Dentre essas ações, em São Paulo, foi realizada uma intervenção direta em outdoors, na Avenida Paulista, que tratavam a mulher como mercadoria.

A formação de batucadas e o fortalecimento das que já existiam foram importantes para afirmar a ofensiva como uma ação feminista na qual há uma grande participação das jovens na MMM. No FSM de 2005, várias atividades foram realizadas a partir do acúmulo das ações da ofensiva. A batucada se tornou uma marca de atuação da Marcha. No $1^{\circ}$ Encontro Nacional da MMM, realizado em 2006, em Belo Horizonte, houve um avanço na formulação dos conteúdos que trabalhamos na ofensiva, aprofundando a relação com a luta contra o livrecomércio e a OMC. Também foram debatidas formas de criar novas referências culturais, novas práticas e maneira de lazer que se combinam com a crítica da indústria cultural, da imposição de padrões de beleza e comportamento, e dos valores da sociedade de mercado. Em abril de 2008, numa reunião nacional das jovens na MMM, decidiu-se intensificar as nossas atividades, atualizar os conteúdos abordados no tema da mercantilização e ampliar nosso foco de ação nos temas da prostituição, do tráfico de mulheres e das transnacionais. Nossa estratégia para realizar essas tarefas é estabelecer uma dinâmica frequente de troca de informações entre os estados para socializar as atividades realizadas. Para viabilizar esse intercâmbio, utilizaremos o sítio eletrônico (blog) 
e outras formas de comunicação. Outra tarefa dessa retomada é a rearticulação das batucadas nos estados, recuperando e acentuando seu sentido de aglutinador políico, além de um espaço permanente de auto-organização. A luta contra a sociedade de mercado e a resistência à mercantilização do corpo e da vida das mulheres seguem como um eixo fundamental para uma ação feminista que incorpore a perspectiva de classe e seja protagonista de uma transformação profunda da ordem social global, ou seja, para a construção de um feminismo não institucionalizado e militante.

SRF: Nalu, agradecemos seu interesse e disponibilidade em dialogar conosco. Realmente, acreditamos que o público acadêmico, as feministas acadêmicas, que são grande parte do público da Revista de Estudos Feministas (REF), muito se beneficiarão de conhecer sua trajetória e de aprender com os posicionamentos da SOF e da Marcha. Grata mesmo por essa dádiva! 